\title{
Population Pharmacokinetics and Dosing Simulations of Ceftriaxone in Critically III Patients Receiving Extracorporeal Membrane Oxygenation (An ASAP ECMO Study)
}

\author{
Vesa Cheng ${ }^{1,2,3}$. Mohd H. Abdul-Aziz ${ }^{1}$. Fay Burrows ${ }^{4} \cdot$ Hergen Buscher $^{5,6} \cdot$ Young-Jae Cho $^{7} \cdot$ Amanda Corley $^{8}$. \\ Eileen Gilder ${ }^{9}$. Hyung-Sook Kim ${ }^{10}$. Sung Yoon Lim $^{7}$. Shay McGuinness ${ }^{9} \cdot$ Rachael Parke $^{9,11}$. Claire Reynolds ${ }^{5}$. \\ Sam Rudham ${ }^{5}$. Steven C. Wallis ${ }^{1}$. Susan A. Welch ${ }^{4}$. John F. Fraser 2,12,13,14 • Kiran Shekar 2,12,13,14 . \\ Jason A. Roberts ${ }^{1,15,16}$ on behalf of ASAP ECMO Investigators
}

Accepted: 21 December 2021 / Published online: 6 March 2022

(c) The Author(s) 2022, corrected Publication 2022

\begin{abstract}
Background Despite the surge in use of extracorporeal membrane oxygenation (ECMO) in the adult intensive care unit, little guidance is available on the appropriate dosing of antimicrobials in this setting. Ceftriaxone is an antimicrobial with a high affinity to plasma protein, a property identified in the literature as susceptible to sequestration into extracorporeal circuits and hypothesised to require dosage adjustments in this setting.

Objective The aim of this study was to describe the pharmacokinetics of ceftriaxone and identify the best dosing regimen for critically ill adult patients receiving ECMO.

Methods Serial blood samples were taken from patients receiving both ECMO and ceftriaxone. Total and unbound drug concentrations were measured in plasma by chromatographic assay and analysed using a population pharmacokinetic approach with Pmetrics $^{\circledR}$. Dosing simulations were performed to identify the optimal dosing strategy: 60 and 100\% of time with free (unbound) drug concentration exceeding the minimum inhibitory concentration $\left(f \mathrm{~T}_{>\mathrm{MIC}}\right)$.

Results In total, 14 patients were enrolled, of which three were receiving renal replacement therapy (RRT). Total and unbound ceftriaxone was best described in a two-compartment model with total body weight, serum albumin concentrations, creatinine clearance $(\mathrm{CrCL})$, and the presence of RRT included as significant predictors of pharmacokinetics. Patients not on RRT generated a mean renal clearance of $0.90 \mathrm{~L} / \mathrm{h}$, non-renal clearance of $0.33 \mathrm{~L} / \mathrm{h}$, and central volume of distribution of $7.94 \mathrm{~L}$. Patients on RRT exhibited a mean total clearance of $1.18 \mathrm{~L} / \mathrm{h}$. ECMO variables were not significant predictors of ceftriaxone pharmacokinetics. Steady-state dosing simulations found that dosages of $1 \mathrm{~g}$ every $12 \mathrm{~h}$ and $2 \mathrm{~g}$ every $24 \mathrm{~h}$ achieved $>90 \%$ probabilities of target attainment in patients with CrCL of $0 \mathrm{~mL} / \mathrm{min}$ with RRT and 30 and $100 \mathrm{~mL} / \mathrm{min}$ and various serum albumin concentrations (17 and $26 \mathrm{~g} / \mathrm{L}$ ).

Conclusions Dosing recommendations for critically ill adult patients not on ECMO appear to be sufficient for patients on ECMO. Patients exhibiting augmented renal clearance $(>130 \mathrm{~mL} / \mathrm{min})$ or treatment of less susceptible pathogens may require higher doses, which requires further investigation.
\end{abstract}

\section{Background}

Achieving optimal antimicrobial exposure is challenging and may be complicated by extreme physiological derangements in critically ill patients [1]. Furthermore, it has been hypothesised that extracorporeal membrane oxygenation (ECMO) further augments exposure, although the possible

Jason A. Roberts

j.roberts2@uq.edu.au

Extended author information available on the last page of the article mechanisms have yet to be elucidated [2-4]. These changes have been hypothesised to be related to the drug's physicochemical properties, namely lipophilicity or a high degree of protein binding $[5,6]$.

Ceftriaxone is a hydrophilic drug with a octanol water partition coefficient $(\log P)$ of -1.7 [7]. It is one of the few $\beta$-lactams with a high affinity to plasma protein $(85-95 \%)$ [6-8] and may therefore be vulnerable to ECMO-related pharmacokinetic changes. Optimal ceftriaxone activity has been associated with the percentage of time that the free (unbound) drug concentration exceeds the minimum inhibitory concentration (MIC) of the target pathogen $\left(\% f \mathrm{~T}_{>\mathrm{MIC}}\right)$ 


\section{Key Points}

Extracorporeal membrane oxygenation (ECMO) variables were not significant predictors of ceftriaxone pharmacokinetics.

Dosing recommendations for critically ill adult patients not on ECMO provide good probabilities of target attainment in critically ill adult patients on ECMO.

[9]. Pre-clinical studies have suggested that $60-70 \% f \mathrm{~T}_{>\mathrm{MIC}}$ is associated with optimal bactericidal activity [10]. The probability of attaining these targets can be affected by renal function, renal replacement therapy (RRT) [7, 11, 12], and hypoalbuminemia [13, 14].

There is a gap in the literature requiring robust evidence that conventional dosing regimens of 1-2 g every 12-24 h will achieve the requisite target for maximal patient outcomes in critically ill adults receiving ECMO. Therefore, data to guide the optimal use of ceftriaxone in this patient population are urgently needed to optimise patient outcomes. The ASAP ECMO (Antibiotic, Sedative and Analgesic Pharmacokinetics during Extracorporeal Membrane Oxygenation) study was designed to describe the pharmacokinetics of commonly used drugs in adult patients receiving ECMO [15]. The aim of the present paper was to describe the population pharmacokinetics of ceftriaxone in critically ill adult patients receiving ECMO and to identify optimised dosing strategies in this patient population.

\section{Methods}

\subsection{Setting}

This article is part of the ASAP ECMO study, which was a prospective, open-labelled, multi-centre pharmacokinetic study conducted at five intensive care units (ICUs) across Australia, New Zealand, South Korea, and Switzerland from November 2012 to November 2019. A detailed study protocol and general results have been published elsewhere and are only discussed briefly here [15]. Ethical approval was provided by the lead site (The Prince Charles Hospital, Brisbane, Australia [HREC/11/QPCH/121]), with individual institutional approval obtained according to local protocols: Auckland City Hospital, Auckland, New Zealand (LRS/12/06/020/AM08); The Alfred Hospital, Melbourne, Australia (541/12); Bern University Hospital, Bern, Switzerland (2017-01315); Seoul National University Bundang Hospital, Seoul, Republic of Korea (B-1804/465305); St Vincent's Hospital, Sydney, Australia (HREC/11/
SVH/97). Written informed consent was acquired from each participant's next of kin.

\subsection{Study Population}

ICU patients aged 18-90 years who were receiving ceftriaxone whilst undergoing ECMO for respiratory and/or cardiac dysfunction were eligible for inclusion. We excluded patients who had a known allergy to the study drug, were pregnant, had bilirubin $>150 \mu \mathrm{mol} / \mathrm{L}$, had received ongoing massive blood transfusion ( $>50 \%$ blood volume) in the preceding $8 \mathrm{~h}$, or had received therapeutic plasma exchange in the preceding $24 \mathrm{~h}$.

\subsection{Ceftriaxone Dosing and Administration}

Ceftriaxone was reconstituted and administered intravenously according to local hospital protocols.

\subsection{Study Procedures/Protocol}

Pharmacokinetic sampling was performed on one or two dosing occasions after the patient was stabilised on ECMO (i.e. not receiving ongoing acute resuscitation). Blood samples $(\sim 2 \mathrm{~mL})$ were drawn from an existing arterial line and collected into $2 \mathrm{~mL}$ lithium-heparinised tubes at $0,15,30$, $45,60,90,120,180,360$, and 480 minutes post commencement of infusion.

Blood samples were centrifuged at $3000 \mathrm{~g}$ for $10 \mathrm{~min}$ to separate plasma. Plasma samples were frozen at the study site at $-80{ }^{\circ} \mathrm{C}$. All frozen plasma samples were then couriered to and assayed at the central bioanalysis laboratory at the University of Queensland Centre of Clinical Research, Brisbane, Australia.

Clinical and demographic data were collected and deidentified by trained research staff. Each study site maintained an electronic database for their participants, which was subsequently consolidated into a single database.

\subsection{Ceftriaxone Assay}

Total and unbound concentrations of ceftriaxone in plasma were measured using a validated ultra-high-pressure liquid chromatography-tandem mass spectroscopy method on a Shimadzu Nexera connected to a Shimadzu 8030 + triple quadrupole mass spectrometer (Shimadzu Corp., Kyoto, Japan). Clinical samples were assayed in batches alongside calibrators and quality controls, and the results were subject to batch acceptance criteria.

The unbound ceftriaxone concentrations were analysed using a previously validated and published methodology [16]. The unbound fraction was first isolated by ultrafiltration at $37{ }^{\circ} \mathrm{C}$ with a Centrifree ${ }^{\circledR}$ Ultrafiltration Device 
(Merck Millipore, Tullagreen, Ireland), and the ultrafiltered plasma was then processed as a typical plasma sample to obtain the unbound concentration. Ionisation was by positive mode electrospray. Detection was monitored by multiple reaction monitoring at $\mathrm{m} / \mathrm{z} 554.7 \rightarrow 396.1$ (ceftriaxone) and $557.7 \rightarrow 399.1$ (d3-ceftriaxone). Linearity was validated over the concentration range of $1-200 \mathrm{mg} / \mathrm{L}$ (total) and $0.5-200 \mathrm{mg} / \mathrm{L}$ (unbound). Precision and accuracy were within $7.9 \%$ for total and $10.9 \%$ for unbound analyses at all three concentrations tested. The lower limit of quantitation was $1 \mathrm{mg} / \mathrm{L}$ for the total concentration and $0.5 \mathrm{mg} / \mathrm{L}$ for the unbound concentration.

\subsection{Population Pharmacokinetic Analysis}

Total and unbound ceftriaxone concentrations were comodelled with the Nonparametric Adaptive Grid algorithm within Pmetrics ${ }^{\circledR}$ package for $\mathrm{R}^{\circledR}$ (Los Angeles, CA, USA) [17]. One-, two-, and three-compartment models and both Lambda (additive) and Gamma (multiplicative) error models were tested. Biologically plausible covariates tested were weight, body mass index, age, presence of RRT, serum creatinine, creatinine clearance (CrCL), albumin, ECMO mode and flow rate, and APACHE II (Acute Physiology and Chronic Health Evaluation II) and SOFA (Sequential Organ Failure Assessment) scores. These covariates were tested on the central volume of distribution $\left(\mathrm{V}_{\mathrm{c}}\right)$ and clearance in a forward stepwise manner. CrCL was calculated using the Cockcroft-Gault equation [18] (Eq. 1).

$\operatorname{CrCL}\left(\frac{\mathrm{mL}}{\min }\right)=\frac{(140-\text { age }) \times \text { weight }(\mathrm{kg})}{0.815 \times \text { serum creatinine }\left(\mu \frac{\mathrm{mol}}{\mathrm{L}}\right)} \times 0.85$ if female

If the inclusion of a variable resulted in an increase in the coefficient of determination of the linear regression $\left(R^{2}\right)$ and in a reduction of the bias of the goodness-of-fit plot, as well as a statistically significant reduction in the log-likelihood $(P$ $<0.05$ ), the covariate was supported for inclusion.

Simple and complex ceftriaxone protein-binding models were assessed. A simple binding model related the unbound ceftriaxone concentration to the total ceftriaxone concentration, with an inverse relationship with serum albumin concentration. The complex binding model assessed was derived from a previously published study [19].

\subsubsection{Population Pharmacokinetic Model Evaluation and Diagnostics}

The $R^{2}$ and the bias of the observed versus predicted plots as well as the log-likelihood of each run were considered for the goodness-of-fit evaluation. Predictive performance evaluation was based on mean predicted error (bias) and the mean bias-adjusted prediction error (imprecision) of the population and individual prediction models. The visual predictive check plot and the normalised prediction distribution errors, as well as the Akaike information criterion (AIC), Bayesian information criterion (BIC), and log-likelihood ratio were considered to compare different models.

\subsubsection{Dosing Simulations}

Ceftriaxone dosing regimens in a patient weighing $80 \mathrm{~kg}$ with various serum albumin concentrations ( 17 and $26 \mathrm{~g} / \mathrm{L}$ ) and degrees of renal function (CrCL of $0 \mathrm{~mL} / \mathrm{min}$ with RRT, 30 and $100 \mathrm{~mL} / \mathrm{min}$ ) were evaluated using Monte Carlo simulations in Pmetrics ${ }^{\circledR}$. The dosing simulations $(n=1000)$ included $1 \mathrm{~g}$ (over $5 \mathrm{~min}$ ) and $2 \mathrm{~g}$ (over $30 \mathrm{~min}$ ) every 12 and $24 \mathrm{~h}$, respectively. Unbound concentrations were used to calculate the probability of target attainment (PTA) to account for non-linear binding [20]. For each dosing regimen, the PTA was calculated as the percentage of patients achieving a $60 \% f \mathrm{~T}_{>\text {MIC }}$ and $100 \% f \mathrm{~T}_{>\text {MIC }}$ at various MICs $(0.125-128$ $\mathrm{mg} / \mathrm{L})$ at steady state $(72-96 \mathrm{~h})$.

\section{Results}

\subsection{Population Characteristics}

A total of 14 patients with 129 plasma samples were included in this analysis. Table 1 shows the baseline characteristics and clinical information of the included patients. The median age was 36 years (interquartile range 34-52), and half the patients were males. Three patients were on concomitant RRT. In the non-RRT group, the median CrCL was $71 \mathrm{~mL} / \mathrm{min}$ (interquartile range 57-143), and the mean daily dose was $2286 \pm$ standard deviation (SD) $994.5 \mathrm{mg}$. Ceftriaxone was administered as an intermittent infusion over a mean duration of $0.27 \pm 0.29 \mathrm{~h}$.

\subsection{Pharmacokinetic Model Building}

The population pharmacokinetic model that best described the data was a two-compartment model, where the $V_{\mathrm{c}}$ was normalised to the mean weight $(80 \mathrm{~kg})$ of the study cohort. ECMO modality and flow rates were not significant predictors of ceftriaxone pharmacokinetics. The inclusion of the complex binding equation improved the fit compared with the simple binding model ( $\Delta$ AIC $-218, \Delta \mathrm{BIC}-218$ ). The inclusion of the covariates below similarly improved the fit compared with the base model ( $\triangle \mathrm{AIC}-58, \Delta \mathrm{BIC}$ -55 ). Equation (3) represents the complex protein binding model, which was based on previously published drug-albumin binding equations [19]. The normalised $V_{\mathrm{c}}$ was used to predict the protein binding characteristic, $B_{\max }$, which 
Table 1 Baseline characteristics, clinical information of the studied data $^{\mathrm{a}}$ population and relevant ECMO

\begin{tabular}{|c|c|}
\hline Demographic and ECMO data & Result $(n=14)$ \\
\hline \multicolumn{2}{|l|}{ Demographic characteristics } \\
\hline Male & $7(50)$ \\
\hline Age, years & $36(34-52)$ \\
\hline Weight $(\mathrm{kg})$ at admission & $76(68-89)$ \\
\hline Body mass index $\left(\mathrm{kg} / \mathrm{m}^{2}\right)$ & $26(23-28)$ \\
\hline Number of patients on RRT & $3(21)$ \\
\hline CVVH & $1(33)$ \\
\hline CVVHD & $1(33)$ \\
\hline CVVHDF & $1(33)$ \\
\hline \multicolumn{2}{|c|}{ No. of patients by indication for ECMO } \\
\hline Respiratory failure & $9(64)$ \\
\hline Cardiogenic shock & $2(14)$ \\
\hline Cardiac arrest & $2(14)$ \\
\hline Heart transplant & $1(7)$ \\
\hline \multicolumn{2}{|l|}{ Illness severity score } \\
\hline APACHE II (on admission) & $17(14-19)$ \\
\hline SOFA (on sampling day) & $8(6-11)$ \\
\hline $\mathrm{CrCL}(\mathrm{mL} / \mathrm{min})^{\mathrm{b}}$ & $71(57-143)$ \\
\hline Albumin $(\mathrm{g} / \mathrm{L})$ & $27(22-30)$ \\
\hline Bilirubin $(\mu \mathrm{mol} / \mathrm{L})$ & $16(11-28)$ \\
\hline Total protein $(\mathrm{g} / \mathrm{L})$ & $52(50-56)$ \\
\hline Urea $(\mathrm{mmol} / \mathrm{L})$ & $7(5-11)$ \\
\hline \multicolumn{2}{|c|}{ No. of patients by dosing regimen administered ${ }^{\mathrm{a}}$} \\
\hline $1 \mathrm{~g} \mathrm{q} 24 \mathrm{~h}$ & 2 (14), of which 1 (7) on RRT \\
\hline $1 \mathrm{~g} \mathrm{q} 12 \mathrm{~h}$ & 8 (57), of which 2 (14) on RRT \\
\hline $2 \mathrm{~g} \mathrm{q} 24 \mathrm{~h}$ & $1(7)$ \\
\hline $2 \mathrm{~g} \mathrm{q} 12 \mathrm{~h}$ & $3(21)$ \\
\hline \multicolumn{2}{|l|}{ ECMO circuit data } \\
\hline \multicolumn{2}{|l|}{ ECMO modality } \\
\hline Veno-venous & $9(64)$ \\
\hline Veno-arterial & $5(36)$ \\
\hline \multicolumn{2}{|l|}{ ECMO pump } \\
\hline Jostra Rota flow & $11(79)$ \\
\hline CardioHelp & $2(14)$ \\
\hline Levitronix Centrimag & $1(7)$ \\
\hline \multicolumn{2}{|l|}{ ECMO oxygenator } \\
\hline Maquet Quadrox & $10(71)$ \\
\hline Medos Hilite & $3(21)$ \\
\hline Medtronic affinity & $1(7)$ \\
\hline Flow rate $(\mathrm{L} / \mathrm{min})$ & $4.2(3.2-5.2)$ \\
\hline Days on ECMO before sampling & $3(1-4)$ \\
\hline
\end{tabular}

APACHE II acute physiology and chronic health evaluation II score, $\mathrm{CrCL}$ creatinine clearance, $\mathrm{CVVH}$ continuous venovenous haemofiltration, $C V V H D$ continuous venovenous haemodialysis, $C V V H D F$ continuous venovenous haemodiafiltration, $E C M O$ extracorporeal membrane oxygenation, $R R T$ renal replacement therapy, SOFA sequential organ failure assessment

${ }^{\mathrm{a}}$ Data are presented as median (interquartile range) or $\mathrm{n}(\%)$ unless otherwise indicated

${ }^{b}$ Data for 11 patients not on RRT

represented the maximal binding to albumin and was calculated based on the serum concentration of albumin by the molecular mass of ceftriaxone and albumin (554.58 and
66,500 Dalton, respectively) [13]. $\beta$ represents the number of ceftriaxone-binding sites on albumin and the normalised $V_{\mathrm{c}}\left(V_{\mathrm{wt}}\right) . \mathrm{CL}_{\mathrm{t}}(\mathrm{L} / \mathrm{h})$ represents total clearance as a function of 
renal clearance $\left(\mathrm{CL}_{\mathrm{r}}\right)$, non-renal clearance $\left(\mathrm{CL}_{\mathrm{nr}}\right)$, and dialytic clearance $\left(\mathrm{CL}_{\mathrm{rrt}}\right)$. The final error model was a gamma (multiplicative) of 3:

$V_{\mathrm{wt}}=V_{\mathrm{c}} \times\left(\frac{\text { Weight }}{80}\right)^{0.75}$,

$B_{\max }=\operatorname{Alb} \times\left(\frac{554.6}{66,500}\right) \times 1000 \times \beta \times V_{\mathrm{wt}}$,

$\mathrm{CL}_{\mathrm{t}}=\mathrm{CL}_{\mathrm{nr}}+\mathrm{CL}_{\mathrm{r}} \times\left(\frac{\mathrm{CrCL}}{94.6}\right)$,

if patient on RRT : $\mathrm{CL}_{\mathrm{t}}=\mathrm{CL}_{\mathrm{nr}}+\mathrm{CL}_{\mathrm{rrt}}$,

$k_{\mathrm{e}}=\frac{\mathrm{CL}_{\mathrm{t}}}{V_{\mathrm{wt}}}$.

Table 2 shows the pharmacokinetic parameter estimates of the final population pharmacokinetic model.

Figure 1 and file 1 in the electronic supplementary material show the diagnostic plots for the final pharmacokinetic model.

\subsection{Dosing Simulations}

Figures 2 and 3 show the PTA for various simulated dosing regimens at steady state to achieve $60 \% \mathrm{f}_{>\mathrm{MIC}}$ and $100 \% \mathrm{f}_{>\mathrm{MIC}}$. Based on our dosing simulations, the $1 \mathrm{~g}$ every $12 \mathrm{~h}$ and $2 \mathrm{~g}$ every $24 \mathrm{~h}$ dosing regimens achieved $>90 \%$ PTA against pathogens with an MIC $\leq 0.5 \mathrm{mg} / \mathrm{L}$ in

Table 2 Pharmacokinetic parameter estimates for the final ceftriaxone pharmacokinetic model

\begin{tabular}{lrrr}
\hline Parameter & \multicolumn{1}{c}{ Mean $\pm \mathrm{SD}$} & $\mathrm{CV}(\%)$ & \multicolumn{1}{c}{ Median } \\
\hline $\mathrm{CL}_{\mathrm{r}}(\mathrm{L} / \mathrm{h})$ & $0.90 \pm 0.47$ & 52.58 & 1.00 \\
$\mathrm{CL}_{\mathrm{nr}}(\mathrm{L} / \mathrm{h})$ & $0.33 \pm 0.24$ & 70.84 & 0.19 \\
$\mathrm{CL}_{\mathrm{rrt}}(\mathrm{L} / \mathrm{h})$ & $0.85 \pm 0.49$ & 57.64 & 0.89 \\
$V_{\mathrm{c}}(\mathrm{L})$ & $7.94 \pm 1.93$ & 24.31 & 7.82 \\
$k_{\mathrm{CP}}\left(\mathrm{h}^{-1}\right)$ & $1.94 \pm 2.60$ & 134.24 & 0.92 \\
$k_{\mathrm{PC}}\left(\mathrm{h}^{-1}\right)$ & $0.77 \pm 0.55$ & 71.99 & 0.67 \\
$k_{\mathrm{on}}\left(\mathrm{h}^{-1}\right)$ & $4.97 \pm 4.61$ & 21.28 & 3.08 \\
$k_{\text {off }}\left(\mathrm{h}^{-1}\right)$ & $20,397.60 \pm 5359.50$ & $28,724,219.86$ & $19,840.04$ \\
$\beta$ & $1.39 \pm 0.43$ & 0.18 & 1.52 \\
\hline
\end{tabular}

$\beta$ number of ceftriaxone binding sites per albumin molecule, $C L_{n r}$ ceftriaxone non-renal clearance, $C L_{r}$ ceftriaxone renal clearance, $C L_{r r t}$ ceftriaxone dialytic and residual clearance, $C V$ coefficient of variation, $k_{C P}$ constant for distribution of ceftriaxone from the central to the peripheral compartment, $k_{\text {off }}$ constant for ceftriaxone disassociation affinity off albumin, $k_{\text {on }}$ constant for ceftriaxone binding affinity onto albumin, $k_{P C}$ constant for distribution of ceftriaxone from the peripheral to the central compartment, $S D$ standard deviation, $V_{c}$ volume of distribution of the central compartment all six simulated scenarios. Excessive ceftriaxone exposure, deemed to be total trough concentrations $>100 \mathrm{mg} / \mathrm{L}$ [21], were demonstrated to be unlikely in the simulated patients.

\section{Discussion}

This is the first study to describe ceftriaxone population pharmacokinetics in patients on ECMO and provides dosing recommendations for this patient population. Ex vivo data suggest that drugs with high plasma protein binding (e.g. ceftriaxone) are vulnerable to ECMO sequestration and drug loss, reducing the probability of achieving optimal exposures [5-7]. However, our analysis demonstrated that ECMO had minimal impact on ceftriaxone pharmacokinetics and that conventional dosing strategies for critically ill patients can therefore be reliably applied for patients receiving ECMO.

A substantial drug loss (20\%) of ceftriaxone was reported in an ex vivo ECMO circuit experiment [5] and was
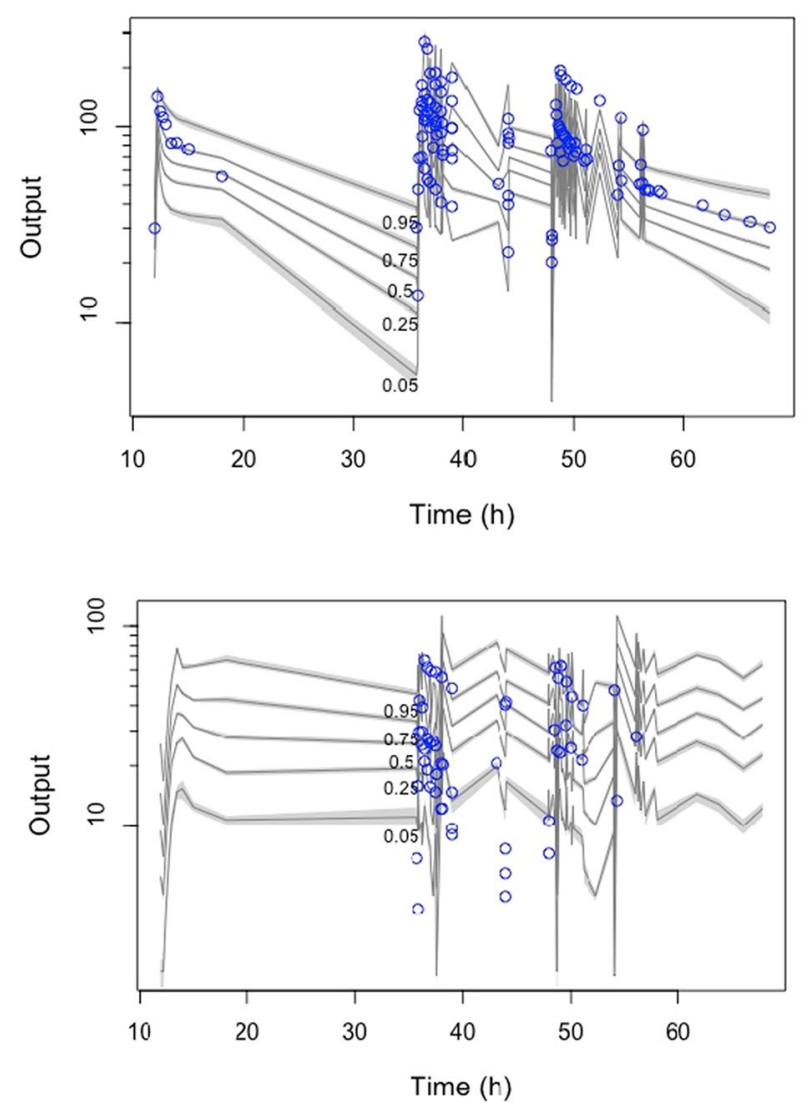

Fig. 1 Visual predictive check associated with the final population pharmacokinetic model of total concentrations (top) and unbound concentrations (bottom) ( $x$-axes indicated time in hours, and $y$-axes indicate ceftriaxone concentration in $\mathrm{mg} / \mathrm{L}$ ). Open circles represent the observed data, and the lines represent the 5th, 25th, 50th, 75th, and $95 \%$ percentiles of the simulated plasma concentrations $(n=$ 1000) 
A: $\mathrm{CrCL} 30 \mathrm{~mL} / \mathrm{min}$, Albumin $26 \mathrm{~g} / \mathrm{L}$

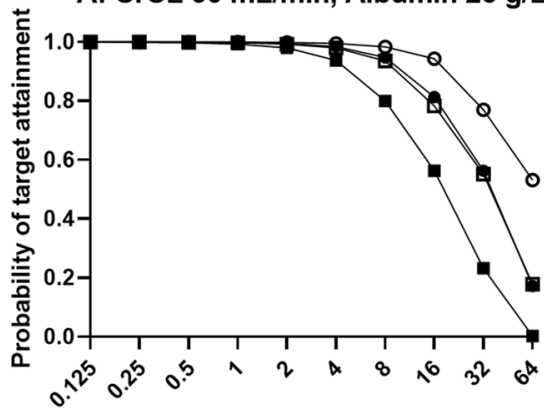

MIC (mg/L)

C: CrCL $100 \mathrm{~mL} / \mathrm{min}$, Albumin $26 \mathrm{~g} / \mathrm{L}$

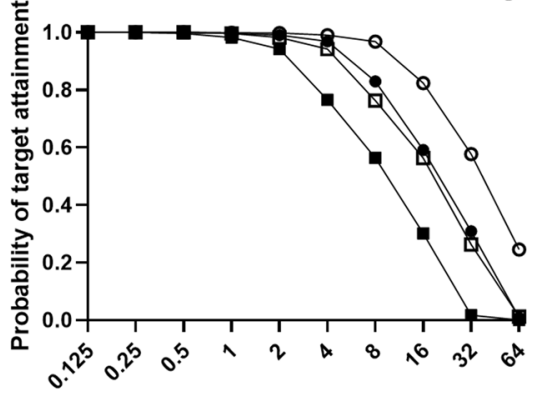

MIC (mg/L)

E: CrCL $30 \mathrm{~mL} / \mathrm{min}$, Albumin $17 \mathrm{~g} / \mathrm{L}$

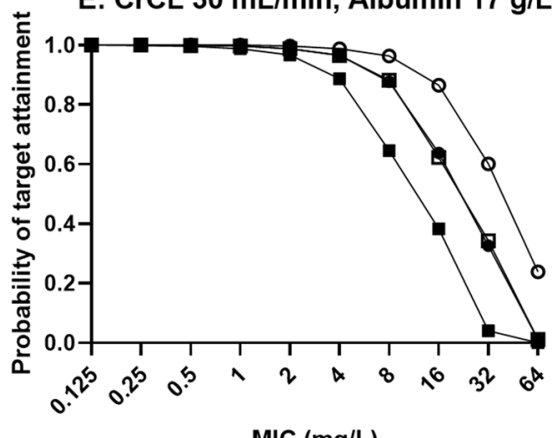

MIC (mg/L)

G: CrCL $100 \mathrm{~mL} / \mathrm{min}$, Albumin $17 \mathrm{~g} / \mathrm{L}$

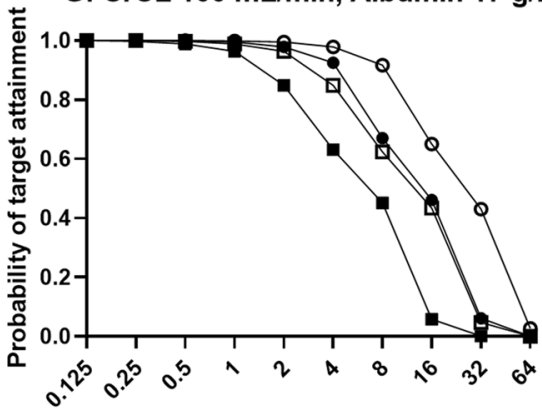

$\operatorname{MIC}(\mathrm{mg} / \mathrm{L})$
B: $\mathrm{CrCL} 30 \mathrm{~mL} / \mathrm{min}$, Albumin $26 \mathrm{~g} / \mathrm{L}$

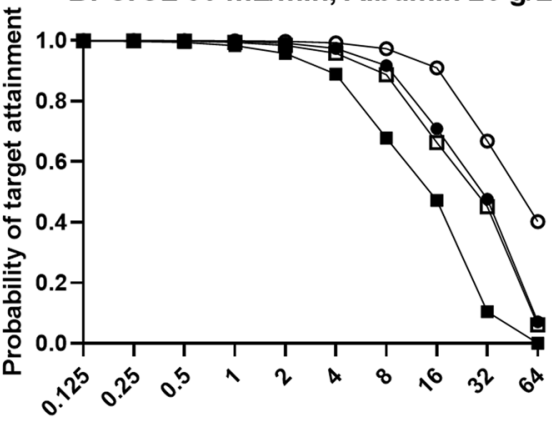

$\operatorname{MIC}(\mathrm{mg} / \mathrm{L})$

D: CrCL $100 \mathrm{~mL} / \mathrm{min}$, Albumin $26 \mathrm{~g} / \mathrm{L}$

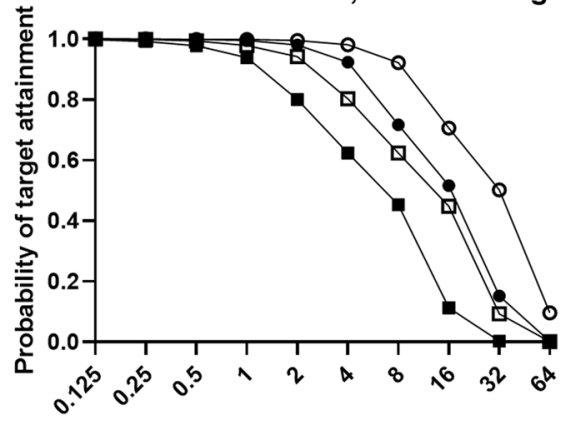

$\operatorname{MIC}(\mathrm{mg} / \mathrm{L})$

F: CrCL $30 \mathrm{~mL} / \mathrm{min}$, Albumin $17 \mathrm{~g} / \mathrm{L}$

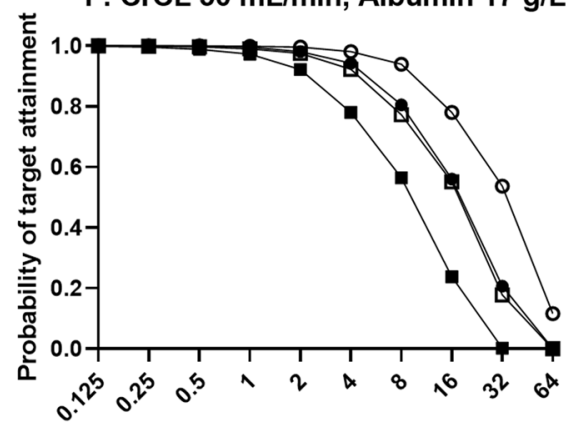

- $1 \mathrm{~g} 12$-hourly

- $1 \mathrm{~g}$ 24-hourly

- 2 g 12 -hourly

४ 2 g 24-hourly

$\operatorname{MIC}(\mathrm{mg} / \mathrm{L})$

$\mathrm{H}:$ CrCL $100 \mathrm{~mL} / \mathrm{min}$, Albumin $17 \mathrm{~g} / \mathrm{L}$

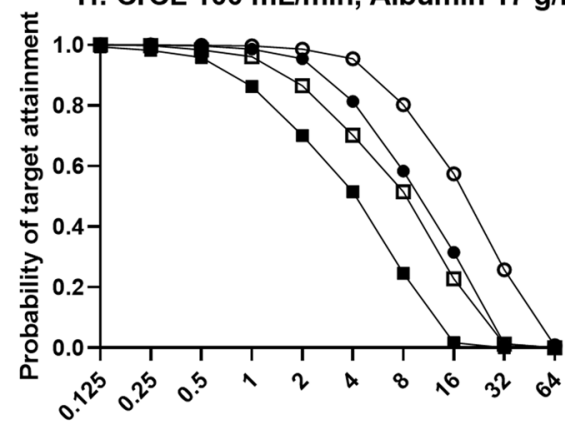

MIC (mg/L)
- $1 \mathrm{~g} 12$-hourly

- $1 \mathrm{~g} 24$-hourly

- 2 g 12 -hourly

๑ 2 g 24-hourly 
4Fig. 2 Probability of target attainment at $60 \% \mathrm{~T}_{>\mathrm{MIC}}$ (left) and $100 \% \mathrm{~T}_{>\text {MIC }}$ (right) for a patient weighing $80 \mathrm{~kg}$ with various degrees of renal function (CrCL 30 and $100 \mathrm{~mL} / \mathrm{min}$ ) and serum albumin concentrations ( 26 and $17 \mathrm{~g} / \mathrm{L}$ ) at steady state with various intermittent ceftriaxone dosing regimens. $\mathrm{CrCL}$ creatinine clearance, $f T_{>M I C}$ time that the free (unbound) drug concentration exceeds the MIC, MIC minimum inhibitory concentration

hypothesised to be due to ceftriaxone's high binding affinity to plasma proteins. On the other hand, another ex vivo study by Leven et al. [22] observed unchanged ceftriaxone concentrations. The contrasting findings from the two studies can possibly be attributed to the type of solution used for circuit priming (normal saline vs. a buffered crystalloid solution) and differing study durations (24 vs. 48 h) [5, 22]. Shekar et al. [6] also performed an ovine ECMO study and identified increased clearance with a trend towards an increased steady state volume of distribution of ceftriaxone secondary to ECMO. However, the transferability of this finding to patients on ECMO is limited by the significant interspecies metabolic and pathophysiological differences.

Our study therefore provides clarification of these findings in the clinical setting. This is the first population pharmacokinetics study to investigate whether ECMO influences ceftriaxone pharmacokinetics in the critically ill adult population. We found that ECMO-related variables were not significant predictors of ceftriaxone pharmacokinetics. The significant covariates identified in this study were weight, $\mathrm{CrCL}$, the presence of RRT, and serum albumin concentration. These factors are common predictors of pharmacokinetics in the critically ill population exhibiting severe physiological changes secondary to shock and multi-organ failure [12]. Although these factors have been well defined in critically ill studies, this is the first study to describe them in an ECMO cohort.

When comparing our estimates with a population pharmacokinetics study by Joynt et al. [11] in critically ill adult patients, our clearance was lower (2.22 vs. $1.23 \mathrm{~L} / \mathrm{h})$. This is likely because we excluded patients with serum creatinine $>120 \mu \mathrm{mol} / \mathrm{L}$ from the study. On the other hand, Joynt et al. [11] generated a very comparable $V_{\mathrm{c}}(0.097$ vs. $0.099 \mathrm{~L} / \mathrm{kg})$. Finally, a population pharmacokinetics study by Garot et al. [12], which recruited 54 critically ill patients with sepsis, found that only CrCL influenced the clearance of ceftriaxone. Although the authors did not identify a significant influence from RRT on ceftriaxone clearance in their population pharmacokinetic model, it is important to note that, conversely, other studies have demonstrated significant ceftriaxone removal during continuous RRT [23-25]. Pea et al. [24] suggested that $\mathrm{CL}_{\text {rrt }}$ almost equated to $\mathrm{CL}_{\mathrm{r}}$ because of significant removal of the drug by continuous RRT. We also observed this phenomenon, as the $\mathrm{CL}_{\mathrm{r}}$ and $\mathrm{CL}_{\text {rrt }}$ estimates were comparable ( 0.90 vs. $0.85 \mathrm{~L} / \mathrm{h})$.
A key strength of our study was the use of a ceftriaxone-albumin binding model, which allowed us to 'model' the relationship and interaction between total and unbound ceftriaxone concentrations. This is an important consideration because the unbound ceftriaxone concentration may not be reliably estimated using published values [20]. Our methodology allowed us to describe the dynamic inter- and intra-patient variability in ceftriaxone and albumin concentrations, particularly in critically ill patients in the ICU. However, some questions about the relationship between different physiological and clinical presentations of critically ill patients and optimal drug dosing remain. Our study produced pharmacokinetic findings similar to those from the aforementioned studies of critically ill non-ECMO patients, suggesting that critical illness itself is the more likely explanation for the observed changes in drug exposure [11, 12].

Overall, our findings were consistent with the results published from a non-compartmental analysis in two patients receiving ceftriaxone while on ECMO [26]. From the steady-state dosing simulations, the $1 \mathrm{~g}$ every $12 \mathrm{~h}$ and $2 \mathrm{~g}$ every $24 \mathrm{~h}$ regimens achieved $>90 \%$ probabilities of efficacy of $60 \% f \mathrm{~T}_{>\text {MIC }}$ and $100 \% f \mathrm{~T}_{>\text {MIC }}$ at an MIC of 1 $\mathrm{mg} / \mathrm{L}$, well above the MIC breakpoints for common pathogens $(0.064-0.125 \mathrm{mg} / \mathrm{L})$ [27]. However, therapeutic drug monitoring should be performed in those with augmented renal clearance $(>130 \mathrm{~mL} / \mathrm{min})$ and/or patients with infections with less susceptible organisms (i.e. higher MICs) to ensure sufficient exposures are achieved.

Our study has several limitations. First, all modalities of RRT were included as a single binary covariate for inclusion, as the small sample size of patients with RRT did not allow for testing of the individual modalities. Future studies should aim to recruit larger patient numbers with different RRT modes to define more robust dosing recommendations for patients on concurrent ECMO and RRT. Second, data on the co-administration of albumin replacement, which is commonly prescribed during fluid resuscitation, were insufficient. Third, the Cockcroft-Gault equation for CrCL estimation is only a mathematical surrogate for true renal function. Future studies may wish to use 24-h urine collection to directly measure $\mathrm{CrCL}$ to overcome this limitation. Finally, the plasma concentrations were used as a surrogate for infection-site concentration. Further studies may be required to better explain the blood-infection-site relationship to ensure that sufficient drug is entering the infection site.

\section{Conclusions}

This is the first population pharmacokinetic model of ceftriaxone in critically ill patients receiving ECMO. Our findings suggested that ECMO does not significantly influence ceftriaxone pharmacokinetics. Observed pharmacokinetic 


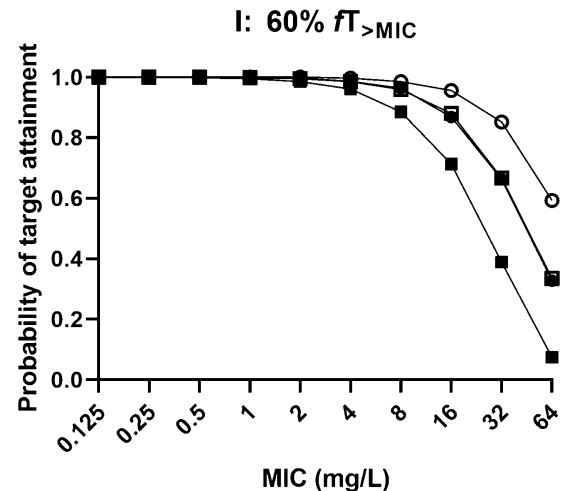

Fig. 3 Probability of target attainment at $60 \% f \mathrm{~T}_{>\mathrm{MIC}}$ (left) and $100 \% \mathrm{~T}_{>\mathrm{MIC}}$ (right) for an anuric patient weighing $80 \mathrm{~kg}$ with a serum albumin concentration of $26 \mathrm{~g} / \mathrm{L}$ on concurrent renal replace-

changes were more likely reflective of physiological alterations related to critical illness. Dosing as per the critically ill population not on ECMO appears highly likely to provide sufficient drug exposures. The steady-state dosing regimen of $1 \mathrm{~g}$ every $12 \mathrm{~h}$ and $2 \mathrm{~g}$ every $24 \mathrm{~h}$ can be used to achieve adequate ceftriaxone exposures against common pathogens with an MIC $\leq 0.5 \mathrm{mg} / \mathrm{L}$. Patients with augmented renal clearance or infections with less susceptible pathogens should be monitored closely with therapeutic drug monitoring to ensure sufficient therapeutic exposures.

Supplementary Information The online version contains supplementary material available at https://doi.org/10.1007/s40262-021-01106-x.

\section{Declarations}

Funding Open Access funding enabled and organized by CAUL and its Member Institutions. This work was supported by The Prince Charles Hospital Research Foundation, Australian and New Zealand Intensive Care Foundation, Australia and New Zealand College of Anaesthetists (S12/001; S13/021), Society of Hospital Pharmacists of Australia, and National Health and Medical Research Council of Australia (APP1079421; APP1099452).

Conflict of interest Vesa Cheng, Mohd H. Abdul-Aziz, Fay Burrows, Hergen Buscher, Young-Jae Cho, Amanda Corley, Eileen Gilder, Hyung-Sook Kim, Sung Yoon Lim, Shay McGuinness, Rachael Parke, Claire Reynolds, Sam Rudham, Steven C. Wallis, Susan A. Welch, John F. Fraser, Kiran Shekar, and Jason A. Roberts have no conflicts of interest that are directly relevant to the content of this article.

Availability of data and materials All data generated or analysed during this study are included in this published article and its supplementary information files.

Ethics approval Ethical approval was provided by the lead site (The Prince Charles Hospital, Brisbane, Australia-HREC/11/QPCH/121), with individual institutional approval obtained according to local protocols.

Consent Written informed consent was acquired from each participant's next of kin.

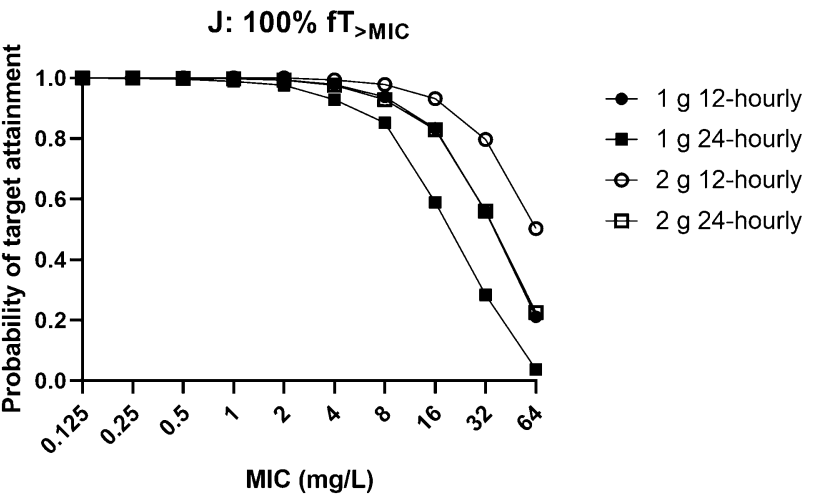

ment therapy. $f T_{>M I C}$ time that the free (unbound) drug concentration exceeds the MIC, MIC minimum inhibitory concentration

Author contributions All authors contributed to the study conception and design. Material preparation and data collection and analysis were performed by Vesa Cheng, Mohd-Hafiz Abdul-Aziz, Jason A. Roberts, and Kiran Shekar. The first draft of the manuscript was written by Vesa Cheng, and all authors commented on subsequent versions. All authors read and approved the final manuscript.

Open Access This article is licensed under a Creative Commons Attribution-NonCommercial 4.0 International License, which permits any non-commercial use, sharing, adaptation, distribution and reproduction in any medium or format, as long as you give appropriate credit to the original author(s) and the source, provide a link to the Creative Commons licence, and indicate if changes were made. The images or other third party material in this article are included in the article's Creative Commons licence, unless indicated otherwise in a credit line to the material. If material is not included in the article's Creative Commons licence and your intended use is not permitted by statutory regulation or exceeds the permitted use, you will need to obtain permission directly from the copyright holder. To view a copy of this licence, visit http://creativecommons.org/licenses/by-nc/4.0/.

\section{References}

1. Abdul-Aziz MH, Lipman J, Mouton JW, Hope WW, Roberts JA. Applying pharmacokinetic/pharmacodynamic principles in critically ill patients: optimizing efficacy and reducing resistance development. Semin Respir Crit Care Med. 2015;36(1):136-53. https://doi.org/10.1055/s-0034-1398490.

2. Shekar K, Fraser JF, Smith MT, Roberts JA. Pharmacokinetic changes in patients receiving extracorporeal membrane oxygenation. J Crit Care. 2012;27(6):741. https://doi.org/10.1016/j.jcrc. 2012.02.013.

3. Bougle A, Dujardin O, Lepere V, Ait Hamou N, Vidal C, Lebreton $\mathrm{G}$, et al. PHARMECMO: therapeutic drug monitoring and adequacy of current dosing regimens of antibiotics in patients on Extracorporeal Life Support. Anaesth Crit Care Pain Med. 2019. https://doi.org/10.1016/j.accpm.2019.02.015.

4. Cheng V, Abdul-Aziz MH, Roberts JA, Shekar K. Overcoming barriers to optimal drug dosing during ECMO in critically ill adult patients. Expert Opin Drug Metab Toxicol. 2018;15(2):103-12. https://doi.org/10.1080/17425255.2019.1563596.

5. Shekar K, Roberts JA, McDonald CI, Ghassabian S, Anstey C, Wallis SC, et al. Protein-bound drugs are prone to sequestration in 
the extracorporeal membrane oxygenation circuit: results from an ex vivo study. Crit Care (London, England). 2015;19:164. https:// doi.org/10.1186/s13054-015-0891-z.

6. Shekar K, Roberts JA, Barnett AG, Diab S, Wallis SC, Fung YL, et al. Can physicochemical properties of antimicrobials be used to predict their pharmacokinetics during extracorporeal membrane oxygenation? Illustrative data from ovine models. Crit Care (London, England). 2015;19:437. https://doi.org/10.1186/ s13054-015-1151-y.

7. Leegwater E, Kraaijenbrink BVC, Moes DJAR, Purmer IM, Wilms EB. Population pharmacokinetics of ceftriaxone administered as continuous or intermittent infusion in critically ill patients. J Antimicrob Chemother. 2020;75(6):1554-8. https://doi.org/10.1093/ jac/dkaa067.

8. Patel IH, Chen S, Parsonnet M, Hackman MR, Brooks MA, Konikoff J, et al. Pharmacokinetics of ceftriaxone in humans. Antimicrob Agents Chemother. 1981;20(5):634-41. https://doi.org/10. 1128/aac.20.5.634.

9. Mouton JW, Dudley MN, Cars O, Derendorf H, Drusano GL. Standardization of pharmacokinetic/pharmacodynamic (PK/PD) terminology for anti-infective drugs: an update. J Antimicrob Chemother. 2005;55(5):601-7. https://doi.org/10.1093/jac/dki079.

10. Craig WA. Pharmacokinetic/pharmacodynamic parameters: rationale for antibacterial dosing of mice and men. Clin Infect Dis. 1998;26(1):1-10.

11. Joynt GM, Lipman J, Gomersall CD, Young RJ, Wong EL, Gin T. The pharmacokinetics of once-daily dosing of ceftriaxone in critically ill patients. J Antimicrob Chemother. 2001;47(4):421-9.

12. Garot D, Respaud R, Lanotte P, Simon N, Mercier E, Ehrmann $S$, et al. Population pharmacokinetics of ceftriaxone in critically ill septic patients: a reappraisal. Br J Clin Pharmacol. 2011;72(5):758-67. https://doi.org/10.1111/j.1365-2125.2011. 04005.x.

13. Schleibinger M, Steinbach CL, Töpper C, Kratzer A, Liebchen U, Kees F, et al. Protein binding characteristics and pharmacokinetics of ceftriaxone in intensive care unit patients. Br J Clin Pharmacol. 2015;80(3):525-33. https://doi.org/10.1111/bcp.12636.

14. Dhanani JA, Ahern B, Lupinsky L, Jackson K, Wallis SC, AbdulAziz $\mathrm{MH}$, et al. Comparative plasma pharmacokinetics of ceftriaxone and ertapenem in normoalbuminemia, hypoalbuminemia, and albumin replacement in a sheep model. Antimicrob Agents Chemother. 2020;64(7):e02584-e2619. https://doi.org/10.1128/ aac.02584-19.

15. Shekar K, Roberts JA, Welch S, Buscher H, Rudham S, Burrows F, et al. ASAP ECMO: antibiotic, sedative and analgesic pharmacokinetics during extracorporeal membrane oxygenation: a multicentre study to optimise drug therapy during ECMO. BMC Anesthesiol. 2012;12:29. https://doi.org/10.1186/1471-2253-12-29.

16. Tsai D, Stewart P, Goud R, Gourley S, Hewagama S, Krishnaswamy $S$, et al. Total and unbound ceftriaxone pharmacokinetics in critically ill Australian indigenous patients with severe sepsis. Int J Antimicrob Agents. 2016;48(6):748-52. https://doi.org/10. 1016/j.ijantimicag.2016.09.021.

17. Neely MN, van Guilder MG, Yamada WM, Schumitzky A, Jelliffe RW. Accurate detection of outliers and subpopulations with Pmetrics, a nonparametric and parametric pharmacometric modeling and simulation package for R. Ther Drug Monit. 2012;34(4):46776. https://doi.org/10.1097/FTD.0b013e31825c4ba6.

18. Cockcroft DW, Gault MH. Prediction of creatinine clearance from serum creatinine. Nephron. 1976;16(1):31-41.

19. Byrne CJ, Parton T, McWhinney B, Fennell JP, O’Byrne P, Deasy E, et al. Population pharmacokinetics of total and unbound teicoplanin concentrations and dosing simulations in patients with haematological malignancy. J Antimicrob Chemother. 2018;73(4):995-1003. https://doi.org/10.1093/jac/dkx473.

20. Wong G, Briscoe S, Adnan S, McWhinney B, Ungerer J, Lipman $\mathrm{J}$, et al. Protein binding of beta-lactam antibiotics in critically ill patients: can we successfully predict unbound concentrations? Antimicrob Agents Chemother. 2013;57(12):6165-70. https://doi. org/10.1128/AAC.00951-13.

21. Le Turnier P, Navas D, Garot D, Guimard T, Bernard L, Tattevin $\mathrm{P}$, et al. Tolerability of high-dose ceftriaxone in CNS infections: a prospective multicentre cohort study. J Antimicrob Chemother. 2019;74(4):1078-85. https://doi.org/10.1093/jac/dky553.

22. Leven C, Fillâtre P, Petitcollin A, Verdier M-C, Laurent J, Nesseler N, et al. Ex vivo model to decipher the impact of extracorporeal membrane oxygenation on beta-lactam degradation kinetics. Ther Drug Monit. 2017;39(2):180-4.

23. Kroh UF, Lennartz H, Edwards DJ, Stoeckel K. Pharmacokinetics of ceftriaxone in patients undergoing continuous veno-venous hemofiltration. J Clin Pharmacol. 1996;36(12):1114-9. https://doi. org/10.1002/j.1552-4604.1996.tb04164.x.

24. Pea F, Viale P, Pavan F, Furlanut M. Pharmacokinetic considerations for antimicrobial therapy in patients receiving renal replacement therapy. Clin Pharmacokinet. 2007;46(12):997-1038.

25. Matzke GR, Frye RF, Joy MS, Palevsky PM. Determinants of ceftriaxone clearance by continuous venovenous hemofiltration and hemodialysis. Pharmacotherapy. 2000;20(6 I):635-43. https:// doi.org/10.1592/phco.20.7.635.35170.

26. Gijsen M, Annaert P, Shekar K, Roberts JA, Wauters J, Spriet I. Letter to the editor regarding: ceftriaxone exposure in patients undergoing extracorporeal membrane oxygenation. Int J Antimicrob Agents. 2021;57(5): 106326. https://doi.org/10.1016/j.ijant imicag.2021.106326.

27. European Committee on Antimicrobial Susceptibility Testing. Breakpoint tables for interpretation of MICs and zone diameters. https://mic.eucast.org/Eucast2/ (2020). Accessed 10 Aug 2020. 


\section{Authors and Affiliations}

\section{Vesa Cheng ${ }^{1,2,3}$. Mohd H. Abdul-Aziz ${ }^{1}$. Fay Burrows ${ }^{4} \cdot$ Hergen Buscher $^{5,6} \cdot$ Young-Jae Cho ${ }^{7} \cdot$ Amanda Corley $^{8}$. Eileen Gilder ${ }^{9}$. Hyung-Sook Kim ${ }^{10}$. Sung Yoon Lim $^{7}$. Shay McGuinness ${ }^{9} \cdot$ Rachael Parke $^{9,11}$. Claire Reynolds ${ }^{5}$. Sam Rudham ${ }^{5}$. Steven C. Wallis ${ }^{1}$. Susan A. Welch ${ }^{4}$. John F. Fraser $2,12,13,14$. Kiran Shekar 2,12,13,14 . Jason A. Roberts ${ }^{1,15,16}$ on behalf of ASAP ECMO Investigators}

$1 \quad$ University of Queensland Centre for Clinical Research (UQCCR), Faculty of Medicine, The University of Queensland, Brisbane, QLD, Australia

2 Adult Intensive Care Services and Critical Care Research Group, The Prince Charles Hospital, Brisbane, QLD, Australia

3 Department of Anaesthesia and Intensive Care, Faculty of Medicine, Chinese University of Hong Kong, Hong Kong, China

4 Department of Pharmacy, St Vincent's Hospital, Sydney, NSW, Australia

5 Department of Intensive Care Medicine, St Vincent's Hospital, Sydney, NSW, Australia

6 St Vincent's Centre for Applied Medical Research, University of New South Wales, Sydney, NSW, Australia

7 Division of Pulmonary and Critical Care Medicine, Department of Internal Medicine, Seoul National University College of Medicine, Seoul National University Bundang Hospital, Seongnam, Republic of Korea

8 Adult Intensive Care Services, The Prince Charles Hospital, Chermside, Brisbane, QLD, Australia
9 Cardiothoracic and Vascular Intensive Care Unit, Auckland City Hospital, Auckland, New Zealand

10 Department of Pharmacy, Seoul National University Bundang Hospital, Seongnam, Republic of Korea

11 School of Nursing, The University of Auckland, Auckland, New Zealand

12 Faculty of Medicine, The University of Queensland, Brisbane, QLD, Australia

13 Faculty of Health, Queensland University of Technology, Brisbane, QLD, Australia

14 Faculty of Health Sciences and Medicine, Bond University, Gold Coast, QLD, Australia

15 Departments of Intensive Care Medicine and Pharmacy, Royal Brisbane and Women's Hospital, Brisbane, QLD 4029, Australia

16 Division of Anaesthesiology Critical Care Emergency and Pain Medicine, Nîmes University Hospital, University of Montpellier, Nîmes, France 